EVIDENCE BASED PUBLIC HEALTH POLICY AND PRACTICE

\title{
Malaria, from natural to supernatural: a qualitative study of mothers' reactions to fever (Dienga, Gabon)
}

\author{
Hugo Pilkington, Justice Mayombo, Nicolas Aubouy, Philippe Deloron
}

J Epidemiol Community Health 2004;58:826-830. doi: 10.1136/jech.2003.016089

See end of article for authors' affiliations

Correspondence to:

Mr H Pilkington, 30 rue des Jeuneurs, 75002 Paris, France; hugo.pilkington@ club-internet.fr

Accepted for publication 31 January 2004

\begin{abstract}
Objective: Decision making for health care at the household level is a crucial factor for malaria management and control among young children. This study sought to determine exactly how mothers reacted when faced with fever in a child.

Design: Qualitative study based on in depth semistructured interviews of mothers and free form discussion with traditional healers (Nganga).

Setting: Village of Dienga, a rural area of Gabon (Central Africa).

Participants: 12 mothers and three traditional healers.

Results: All mothers thought that fever and malaria were identical. Mothers home treated or went to the village treatment centre, or both, on the last episode of fever, if they judged it to be "natural" fever. However, if fever was thought to be a result of malicious intent, then a Nganga was consulted first. It was believed that strong and above all persistent fever was "supernatural". In this case, traditional treatment was thought to be best.

Conclusions: Results indicate that fever is perceived as a dual condition, with two distinct but non-mutually exclusive aetiologies (either "natural" or from witchcraft). In contrast with what is commonly believed, there seems to be no clear cut distinction between diseases suitable for management by western medicine and diseases to be managed solely by traditional health practitioners. Moreover, these data do not support the commonly held notion that the decision to seek western medicine to treat fever is considered a "last resort". Results strongly imply that some severe cases of fever, being initially considered supernatural, may partially or completely escape medical attention.
\end{abstract}

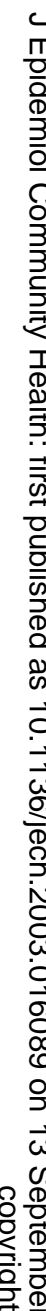

O ne of the most important factors in the success of any malaria management programme is to correctly train decision makers within the family, at household level. In many populations, the wellbeing of the family devolves on the mother. It is thus essential that mothers be correctly trained in the initial recognition and management of malaria related symptoms. ${ }^{12}$

It is now widely recognised that symptoms, signs, classification of illness, and beliefs in a community about illness transmission and treatment differ from biomedical models, and that communication between specialists and local people is often confused. A review of recent literature shows growing interest into understanding health seeking behaviour in general ${ }^{3}$ and the understanding of certain clinical signs (such as fever) from a cultural perspective in particular. $^{5}$ This is important not just for the struggle against malaria, but also for the rapid initial recognition and detection of other commonly fatal febrile illnesses in early childhood by the family. An important objective of these studies is to optimise mothers' health seeking reactions when confronted with fever in a child, ${ }^{6}$ given that African populations are assumed to deem some diseases suitable for management by modern medicine, while others are considered the exclusive domain of traditional health practitioners. It has even been asserted that decisions to seek modern medicine for any illness are taken in last resort, ${ }^{1}$ although research has challenged this simplistic assumption. ${ }^{5-7}$ However, these studies do not specifically address the ethnological determinants ( the culturally tailored concepts or "folk epidemiologies" constructed to explain causal factors of disease and thus put them within local control and understanding) of the potential risk of severe and complicated malaria escaping medical attention.
Mortality rates for children under 5 years of age continue to be very high in sub-Saharan Africa, most countries in the region presenting rates above 100 per thousand. Most of this high mortality is mainly attributable to common treatable and mostly preventable illnesses such as anaemia, pneumonia, diarrhoea, measles, malnutrition, and malaria. ${ }^{8}$ Among these largely treatable and preventable conditions, malaria represents a major public health problem in sub-Saharan Africa, especially in young children, who have not yet acquired a sufficient level of immunity to stop them from developing the severest forms of the disease. Severe Plasmodium falciparum malaria is the commonest cause of death in infants and children in malaria endemic areas. ${ }^{9-12}$ The lack of prompt recognition and treatment of the symptoms of malaria (which overlap with those of other fatal febrile illnesses in early childhood) within the first 24 hours accounts for the greatest proportion of deaths in children. ${ }^{12}{ }^{13}$

In this study, we sought to describe and understand treatment seeking patterns mothers adopted when faced with fever in one of their children in a malaria endemic area.

\section{METHODS}

\section{Setting}

This research is set in the village of Dienga (population 1400 in 1997), located in a malaria endemic area of south eastern Gabon with seasonal transmission (see box 1). ${ }^{14}$

\section{Study design}

We designed a qualitative study based on a semistructured interview of a group of mothers. The principal objective of the study was to describe in the greatest possible detail treatment that had been given to the children during the last febrile episode and where care had been delivered. During initial 
data collection, we quickly realised that additional research was needed into local perceptions of health and disease, so we decided to seek help from local traditional health providers - traditional witch doctors and herbalists known as Ngangas. We discussed with them the data obtained from the interviews with the mothers, separately, after the initial data collection had taken place. They helped us interpret respondents' declarations within their own cultural context and explained various terms and traditions to us. This helped us to understand some of the terms used by the respondents during the interviews, especially "fever" and "malaria". In two cases, we re-interviewed mothers, focusing on the topics we needed clarifying through follow up discussions. The Ngangas did not participate directly in discussions with the mothers at any time (we did not want to run the risk of unconsciously influencing the interviewees' responses).

\section{Sample}

Our sample comprised the 12 mothers of 61 children already engaged in an independent epidemiological study on factors influencing resistance to reinfection with $P$ falciparum after parasite clearance, described elsewhere (see table 1). ${ }^{15}$ While this sample is not a representative sample of the general population of the area, respondents varied in age and socioeconomic status, their individual situations covering the range of characteristics of adult women in the village, as assessed in a previous survey (Renaut A, unpublished data).

Box 1 Medical research in the Nzebi community of Dienga (Gabon)

- The Nzebi (or Niebi) are an indigenous Bantu population whose traditional territory spreads over about $32000 \mathrm{~km}^{2}$ between south eastern Gabon and a small area to the extreme north of the Republic of Congo-Brazzaville. They were roughly estimated to number 60000 in 1982 (for 1014976 inhabitants of Gabon according to the 1993 national census). The village of Dienga, exclusively populated by the Nzebi, is located practically on the borderline between the two countries.

- Partly because of this ethnic homogeneity, the inhabitants took part from 1995 to 2000 in a project named "malaria and genetics", aimed at describing specific immune responses according to individual genetic characteristics, reported elsewhere..$^{15}$ During this period, villagers took part in several epidemiological investigations and received health education on malaria transmission, recognition, and management to optimise reaction towards malaria related symptoms. A previous study of the village in 1995-96 estimated the mean prevalence of $P$ falciparum infection (as assessed by 3014 blood smears) to be $26.8 \%$, and the monthly malaria attack rate (as assessed by the daily surveillance of 228 children) to be 41.4 per thousand. ${ }^{14}$

- A permanent field station was set up in the village by the Centre International de Recherches Médicales de Franceville (CIRMF) and staffed with two villagers who received medical training from CIRMF. The centre provided free diagnosis and treatment of malaria infection during this period.
Table 1 Characteristics of the 12 study participants

\begin{tabular}{|c|c|}
\hline Characteristic & $\begin{array}{l}\text { Number (\%) } \\
12(100)\end{array}$ \\
\hline \multicolumn{2}{|l|}{ Marital status } \\
\hline Single & $1(8)$ \\
\hline Married & $11(92)$ \\
\hline \multicolumn{2}{|l|}{ Family structure } \\
\hline Monogamous & $5(42)$ \\
\hline Polygamous & 7 (58) \\
\hline \multicolumn{2}{|l|}{ Age $(y)$} \\
\hline Mean (range) & $31.1(22-49)$ \\
\hline Mean number of children & 5 \\
\hline \multicolumn{2}{|l|}{ Education* ${ }^{*}$} \\
\hline None & $7(58)$ \\
\hline Primary & $3(25)$ \\
\hline Secondary & 1 (8) \\
\hline Higher & $1(8)$ \\
\hline \multicolumn{2}{|l|}{ Religion } \\
\hline Christian & $5(42)$ \\
\hline Unspecified & $7(58)$ \\
\hline
\end{tabular}

\section{Ethical considerations}

Participants and village officials were informed of the objectives and methods of the study and uses of information they would supply. The mothers gave their consent for participation. Approval was granted by the ethics committee of CIRMF.

\section{Data collection-interviews of mothers}

We interviewed mothers for about two hours either at the CIRMF field station or at home. In general, women were interviewed individually, except when they shared the same husband. We systematically used a bilingual approach, encouraging mothers to communicate in whichever language they were most comfortable (French or Nzebi). A research technician from the same village and speaking both languages fluently (JM) was always present. Responses to items were either transcribed accurately (if in French) or translated (if in Nzebi). After each interview, researchers compiled and read through the data to produce a first synthesis. Data collection took place over a two week period in June 1999.

\section{Data collection-interviews of Ngangas}

We set up a series of focus groups with three local Ngangas, sharing results from the mothers' interviews with them. In

\section{Key points}

- Local explanations for the clinical signs of malaria, especially non-specific ones such as fever, may lead to the attribution of different causes for the disease and thus to different treatments, sought from different sources.

- "Malaria" does not mean malaria in the western sense, but rather "febrile illness".

- The local population undertakes a process of differential diagnosis to distinguish two types of febrile illness with differing aetiologies, either natural or supernatural.

- The local population uses differences in disease severity as important criteria for determining disease aetiology and indicated treatment.

- Some cases of severe and complicated febrile illness are possibly not being brought to medical care. 
turn, the Ngangas' comments were shared with the mothers in free form follow up discussions, whenever necessary, thus helping new themes emerge. This iterative procedure reinforced the strength and validity of the data. ${ }^{16}$

\section{Data analysis}

We developed an initial coding frame for the interviews that we then jointly extended through an iterative process of comparison and evaluation. Several sessions were organised between researchers and the mothers until all agreed that a satisfactory mutual understanding had been reached.

\section{RESULTS}

For clarity, we have grouped results into four main themes, as they emerged from the in depth interviews of the mothers. These are: belief that fever and malaria are identical, perceived origins of different types of fever, mothers' reaction to fever in a child, and decisional criteria used to identify different "types" of fever.

\section{Malaria is fever}

We asked mothers to enumerate the most common health problems in the community. All mothers stated that fever was the most frequent problem within the community, and that this was especially true for children. When we asked what exactly mothers meant by the term "fever", the following were invariably quoted: the body being "hot", and any combination of shivering, headaches, and pains. These three latter signs did not have to be present at the same time as the body temperature increase, however, but usually they were. We also asked mothers what they thought fever was. All mothers replied "malaria". When we probed the meaning of "malaria", mothers responded that malaria was fever. This has already been noted in other studies. ${ }^{17-19}$ In our study, we uncovered no other terms for febrile illnesses comprising these four signs, or any other combination of fever associated signs. For clarity, we shall from now on

\section{Box 2 Selection of participants' responses}

Fever is malaria

Philomène's child, Oscar, was unwell recently. "The child was showing his head and kept sleeping deeply. He was all hot. I think it was malaria."

Simone N's little girl, Maïva, started having headaches and felt cold all over "it was malaria for sure", she said.

Reaction to fever

"When Chris Vadel was sick, I gave him some paracetamol" (Adèle) "I always have Quinimax (injectable quinine) at home, that's what I use. Then I'll take the child to the CIRMF village treatment centre" (Philomène) "I took the child to the CIRMF centre, because he needed a blood test." (Simone M) "My brother sends me Nivaquine from Libreville, I use that and I went to the village centre afterwards." (Marie-Louise)

Decisional criteria/aetiology of fever

"I always go to the village treatment centre. My children have also been seen by the Nganga, because some diseases look just like others, like malaria, but are due to spirits. Only the Nganga can help then. So the best thing is to start with medicine and see what happens. If things get worse, we go to the Nganga." (Bernadette)

"The Nganga is for very bad cases. We wait for the hospital to give medicine first, but then sometimes if the illness won't go away then we have to take the person to see the Nganga. Some illnesses come about because a witch sent them to you." (Jeanne) systematically refer to "fever" when quoting mothers' responses, even when the term actually used was "malaria".

\section{Where fever comes from}

We asked respondents what, in their opinion, actually causes fever. Two separate answers were given. Firstly, all mothers recognised that "small biting animals" (mosquitoes were seldom mentioned in the interviews) could give a person "natural" fever. In this case, mothers said that this was exactly what had been taught to them in the health education campaigns organised by CIRMF on the recognition of malaria related signs. All mothers agreed that medicine given to them was useful and established a clear relation between taking medicine and being relieved of discomfort. Mothers knew that fever could be very crippling and even lethal.

Secondly, it appeared during the course of the interviews that fever also designates a very different and equally incapacitating affliction. Respondents explained that this disorder would show exactly the same set of signs mentioned above, but with far greater intensity. This type of fever is considered to be supernatural in origin: someone had to use witchcraft to inflict it. Respondents thought this was akin to being possessed or more specifically, to being "bewitched". Both types of fever could be present in a person at the same time.

\section{Reaction to fever}

We asked mothers what they did the last time one of their children had fever. Specifically, we sought to describe treatment seeking behaviour when confronted with signs of fever in a child.

The following pattern emerged. When confronted with fever that seemed not too severe, mothers would first either treat the child with any medicine they had at hand (usually paracetamol and sometimes chloroquine tablets or injectable quinine). If they had no medicine at home and/or if fever persisted, then they would seek help at the village health centre. If treatment provided at the centre was deemed to have no effect (see next paragraph), then they would either seek help at the hospital (several hours ride from the village) or at the Nganga. If the child's condition did not improve at the hospital, then it was felt that the best recourse was to consult a Nganga and stop treatment with modern medicine.

\section{Decisional criteria}

We sought to establish what decisional criteria mothers used to assess whether fever in a child was of natural or supernatural origin. This is important, because these criteria seem to determine exactly what type of treatment should be used (see box 2).

The mothers considered that the clearest signs of supernaturally caused disease were either severe symptoms on initiation of illness or failure to respond to initial medical treatment. They explained that these cases would clearly be caused by witchcraft and thus would need attention from the Nganga. The Nganga would be able to provide both relief from the physical suffering and treatment of the cause (that is, the "bewitching") behind it. Modern medicine would be of little or no use. The only exceptions were two mothers who expressed strong Christian beliefs and thus felt that going to see the Nganga was wrong and sinful.

\section{DISCUSSION}

There are three key findings in this study. Firstly, the word "malaria" (at least in this specific group) does not mean malaria in the western sense, but rather "febrile illness" that is, fever. Secondly, the local population does undertake a process of differential diagnosis to distinguish two types of 
febrile illness with differing aetiologies. Thirdly, the local population uses differences in disease severity as important criteria for determining disease aetiology and indicated treatment.

Fever is correctly regarded as a sign needing immediate medical attention. Mothers recognise the need to treat fever promptly. They react swiftly to fever by having the child seen at the village health centre. This indicates to some degree good memory of what was taught about malaria related clinical signs during the health education sessions. Seeking assistance from modern medicine, at least at this stage, is by no means a "last resort" as has also been noted in studies from Zambia, Kenya, and the Philippines. ${ }^{20-23}$ This challenges the simplistic notion that there are clear cut diseases with different names suitable for modern medicine and diseases for traditional healers. ${ }^{1}$

An important aspect of this study is to shed light on the dual aspect of fever as perceived by local populations. In the local conception of the aetiology of febrile illness, it is not one but two conditions needing separate treatment to respond to a very different set of causes: natural on the one hand (thus suitable for treatment by modern medicine), supernatural on the other (and thus needing attention from "spiritual" doctors). Their view is that there is no difference in the types of physical manifestations of the two forms of fever, but that severity of the signs differ. It is believed possible to differentiate them on the basis of initial intensity of fever at onset and duration of fever after medical care has been provided. This means two things. Firstly, according to the apparent efficacy of modern medicine, respondents will decide whether or not their child is suffering from "natural" or "supernatural" fever. Secondly, if a child were to suffer initially from a high fever and/or other intense manifestations of discomfort, then this would be immediately interpreted as a clear sign of supernatural fever. This fits what we know about conceptual models of belief known as medical syncretism: new information from health education campaigns is incorporated into existing models of health and disease. ${ }^{24}$ In this case, new information about the causes and recognition of malaria related signs ("malaria" being used in this case in the western sense) was blended into an existing model of the aetiologies of fever.

In turn, this indicates two important aspects of treatment seeking behaviour. Firstly, we have found here extremely rationally based decision making. On the basis of a set of signs and their degree of perceived intensity, mothers will decide on one or the other of the causal categories. It is this evaluation that will determine course of action, similar to what has been described in Tanzania. ${ }^{25}$ Secondly, it seems that some children with a high and persistent fever have in the past been taken out of hospital or were never even brought to medical attention. Respondents all remembered clearly that this had happened in the past. This was confirmed to us by the Ngangas we spoke to. Mothers knew that these could be signs of severe and complicated malaria (this had been taught to them), but felt that the danger of having being bewitched was greater and was more urgent to deal with.

The implications of these findings extend beyond the domain of malaria control and into the more general one of the reduction of child mortality. Specifically, the Integrated Management of Childhood Illness (IMCI) strategy, which advises health workers and community residents to pursue different treatment for different sets of symptoms, and to use presence or absence of danger signs to guide decisions to refer to higher levels of care, could potentially benefit from small scale, community based investigations into cultural interpretation of specific clinical signs as well as the acceptability of these recommendations. For instance, these data suggest that drug resistance as well as severe malaria may respond best to a dual therapeutic strategy, involving conventional antimalarial drugs and spiritual help provided by community healers.

These findings suggest that some potentially life threatening febrile illnesses are probably not being brought to medical care. Also, data shown here underline what is suspected about the lack of specificity of verbal necropsies used in malaria specific intervention trials..$^{26-28}$

Furthermore, we feel that using traditional healers to help us interpret data is an original and fruitful way of gaining insight into local systems of belief about health and wellbeing. Going through the findings iteratively among coresearchers, with respondents as well as the Ngangas allowed us to attain a good level of theoretical saturation. That is, after several "rounds" of information sharing, no new themes emerged from the data, and all participants felt that the interpretations of the data correctly conveyed what they had meant. ${ }^{29}$

In conclusion, we feel that the evidence we have presented in this research is sufficient to warrant further investigation into the possible risk of some cases of febrile illness going undiagnosed in children because their aetiology is believed to be supernatural.

These cases may well represent treatable episodes of malaria or other childhood infectious diseases: better coordination between local healers and practitioners of western medicine might help reduce the very high mortality burden borne by children in sub-Saharan Africa.

\section{ACKNOWLEDGEMENTS}

We thank the population of Dienga for participation in our study. We also thank Professor Michel Blanchot, director general of CIRMF, for his support of our work, Doris Bonnet for her advice and help in interpreting the data, and Dr Nicholas Freidin for his helpful comments on the draft version of this paper.

\section{CONTRIBUTORS}

HP designed the study, collected and analysed the data, and wrote the paper. JM and NA collected and analysed some of the data. PD analysed some of the data, discussed the findings, and commented on the written paper. HP is the guarantor.

\section{Authors' affiliations}

H Pilkington, J Mayombo, N Aubouy, Centre International de Recherches Médicales de Franceville (CIRMF), Franceville, Gabon P Deloron, Institut de Recherche pour le Developpement (IRD), Paris, France

Funding: the Centre International de Recherches Médicales de Franceville provided funding for this research. CIRMF is financially supported by the government of Gabon, Elf Gabon, and the French Ministère des Affaires Etrangères.

Conflicts of interests: none declared.

\section{REFERENCES}

1 Nchinda TC. Malaria: a reemerging disease in Africa. Emerg Infect Dis 1998;4:398-403.

2 Kidane G, Morrow RH. Teaching mothers to provide home treatment of malaria in Tigray, Ethiopia: a randomised trial. Lancet 2000;356:550-5.

3 Perdiguero E, Bernabeu J, Huertas R, et al. History of health, a valuable tool in public health. J Epidemiol Community Health 2001;55:667-73.

4 Lam TP. Strengths and weaknesses of traditional Chinese medicine and Western medicine in the eyes of some Hong Kong Chinese. J Epidemiol Community Health 2001;55:762-5.

5 McCombie SC. Treatment seeking for malaria: a review of recent research. Soc Sci Med 1996:43:933-45.

6 McCombie SC. Self-treatment for malaria: the evidence and methodological issues. Health Policy Plan 2002;17:333-44.

7 Feyisetan BJ, Asa S, Ebigbola JA. Mothers' management of childhood diseases in Yorubaland: the influence of cultural beliefs. Health Transit Rev 1997; 7:221-34.

8 Murray CJL, Lopez AD, Mathers CD, et al. The global burden of disease 2000 project: aims, methods and data sources. Geneva: WHO, 2001:57. 
9 Breman JG. The ears of the hippopotamus: Manifestations, determinants, and estimates of the malaria burden. Am J Trop Med Hyg 2001;64(suppl):1-11.

10 Snow RW, Craig M, Deichmann U, et al. Estimating mortality, morbidity and disability due to malaria among Africa's non-pregnant population. Bull World Health Organ 1999:77:624-40.

11 Greenwood BM, Bradley AK, Greenwood AM, et al. Mortality and morbidity from malaria among children in a rural area of The Gambia, West Africa. Trans R Soc Trop Med Hyg 1987;81:478-86.

12 Greenwood B. Malaria mortality and morbidity in Africa. Bull World Health Organ 1999:77:617-18.

13 WHO/OMS and UNICEF. The Africa malaria report 2003. Geneva: World Health Organisation, UNICEF, 2003:112.

14 Deloron P, Ringwald P, Luty ÁJ, et al. Relationships between malaria prevalence and malaria-related morbidity in school children from two villages in central Africa. Am J Trop Med Hyg 1999;61:99-102.

15 Domarle O, Migot-Nabias F, Mvoukani JL, et al. Factors influencing resistance to reinfection with Plasmodium falciparum. Am J Trop Med Hyg 1999;61:926-31.

16 Pope C, Ziebland S, Mays N. Qualitative research in health care: analysing qualitative data. BMJ 2000;320:114-16.

17 Mwenesi HA, Harpham T, Marsh K, et al. Perceptions of symptoms of severe childhood malaria among Mijikenda and Luo residents of coastal Kenya. $J$ Biosoc Sci 1995;27:235-44.

18 Tarimo DS, Lwihula GK, Minjas JN, et al. Mothers' perceptions and knowledge on childhood malaria in the holendemic Kibaha district, Tanzania: implications for malaria control and the IMCl strategy. Trop Med Int Health 2000;5: 179-84.
19 Molyneux CS, Mung'Ala-Odera V, Harpham T, et al. Maternal responses to childhood fevers: a comparison of rural and urban residents in coastal Kenya. Trop Med Int Health 1999;4:836-45.

20 Baume C, Helitzer D, Kachur SP. Patterns of care for childhood malaria in Zambia. Soc Sci Med 2000;51:1491-503.

21 Mwenesi H, Harpham T, Snow RW. Child malaria treatment practices among mothers in Kenya. Soc Sci Med 1995;40:1271-7.

22 Espino F, Manderson L. Treatment seeking for malaria in Morong, Bataan, the Philippines. Soc Sci Med 2000;50:1309-16.

23 Miguel CA, Tallo VL, Manderson L, et al. Local knowledge and treatment of malaria in Agusan del Sur, The Philippines. Soc Sci Med 1999;48:607-18.

24 Muela SH, Ribera JM, Mushi AK, et al. Medical syncretism with reference to malaria in a Tanzanian community. Soc Sci Med 2002;55:403-13.

25 Oberlander L, Elverdan B. Malaria in the United Republic of Tanzania: cultural considerations and health-seeking behaviour. Bull World Health Organ 2000;78:1352-7.

26 Snow RW, Armstrong JR, Forster D, et al. Childhood deaths in Africa: uses and limitations of verbal autopsies. Lancet 1992;340:351-5.

27 Alonso PL, Bowman A, Marsh K, et al. The accuracy of the clinical histories given by mothers of seriously ill African children. Ann Trop Paediatr 1987;7:187-9.

28 Thera MA, D'Alessandro U, Thiero M, et al. Child malaria treatment practices among mothers in the district of Yanfolila, Sikasso region, Mali. Trop Med Int Health 2000;5:876-81.

29 Barbour RS. Checklists for improving rigour in qualitative research: a case of the tail wagging the dog? BMJ 2001;322:1115-17.

\section{APHORISM OF THE MONTH}

\section{"Your freedom ends where my nose begins." (USA, Anon)}

A

$\mathrm{t}$ the heart of many public health issues: tobacco control, road safety, sexual behaviour, alcohol and drugs, for example, the tension behind individual and group rights leads to protracted debate. In the current global moves for environmental measures to combat tobacco related disease, the old adage about the limits to personal freedom seems to be carrying particular weight in the arguments about passive smoking and the protection of workers in the hospitality industry. 